\title{
Effects of the Production Environment on the Susceptibility of Rose Flowers to Postharvest Infection by Botrytis cinerea
}

\author{
Philip E. Hammer ${ }^{1}$ and Kathleen B. Evensen \\ Department of Horticulture, The Pennsylvania State University, University Park, PA 16802
}

\begin{abstract}
Additional index words. Rosa hybrida
Abstract. We studied the effects of environmental conditions during production on susceptibility of roses to postharvest infection by $B$. cinerea. For flowers harvested from a commercial greenhouse, susceptibility was linearly correlated $(r=$ 0.97) with mean air velocity during the 5 -week periods before each harvest. Susceptibility was also correlated with mean leaf to air temperature gradient $(r=0.83)$ and inversely correlated with wetness measured on an electronic leaf $(r=-0.92)$, but these correlations were interpreted as secondary effects of the correlation with air movement. Susceptibility was not correlated with temperature, relative humidity $(\mathrm{RH})$, or the other factors measured. In growth chamber experiments, flowers grown under high wind speed $\left(0.55 \mathrm{~m} \cdot \mathrm{s}^{-1}\right)$ were significantly more susceptible to infection than flowers grown under low wind speed $\left(0.18 \mathrm{~m} \cdot \mathrm{s}^{-1}\right)$. High relative humidity during production increased background infection levels (i.e., those infections not caused by laboratory inoculation) but did not affect susceptibility.
\end{abstract}

Environmental conditions during crop production affect the growth and dispersal of pathogens and the susceptibility of host plants to infection. In the specific case of diseases caused by $B$. cinerea Pers.:Fr., the impact of weather conditions and plant canopy microclimates on pathogen growth and disease severity has been studied for several crops (English et al., 1989; Hausbeck and Pennypacker 1991; Jarvis, 1977; Yunis et al., 1994). Indeed, altering the microclimate by canopy management (leaf removal and pruning) is used successfully for controlling Botrytis bunch rot on grapes (Gubler et al., 1987), and the regulation of moisture in storage rooms and packages can prevent postharvest development of Botrytis flower blight on roses (Hammer and Marois, 1989). Heating and venting of greenhouses can prevent Botrytis epidemics, but rising fuel costs in the late 1970s and early 1980s have reduced such practices (Fletcher, 1985). Most of these studies and practices have focused on the direct effects of environmental conditions on the fungus (Jarvis, 1977), and various workers have determined the optimum temperature, light, and moisture ranges for germination, infection, and sporulation by B.cinerea (Carre, 1984; Jarvis, 1977; Verhoeff, 1980).

In contrast, environmental effects on host susceptibility to Botrytis have not been explored thoroughly. Tissue damage by frost, windblown sand or other mechanical agents increases susceptibility as do deficiencies or excesses of certain mineral elements (Jarvis, 1977; Verhoeff, 1980). However, information about the effects of factors such as temperature, humidity, and irradiance on host susceptibility is scarce. Marois et al. (1988) reported that seasonal changes in the susceptibility of rose flowers to infection by B.cinerea were highly correlated with the vapor pressure deficit (VPD) during production. Under California growing conditions,

Received for publication 20 Mar. 1995. Accepted for publication 9 Oct. 1995. This research was supported, in part, by a National Science Foundation Graduate Fellowship, by research grants from the Roses Incorporated Joseph H. Hill Memorial Foundation, and by the generous donation of roses from Dillon Floral Corporation, Bloomsburg, Pa. Rose plants and other materials were donated by the Conard-Pyle Co., Bear Creek Gardens, DeVore Nurseries, Inc., and Grace Sierra. The cost of publishing this paper was defrayed in part by the payment of page charges. Under postal regulations, this paper therefore must be hereby marked advertisement solely to indicate this fact.

${ }^{1}$ Current address: Ciba-Geigy Corporation, P.O. Box 12257, Research Triangle Park, NC 27709-2257. high VPD (higher temperatures and lower humidities) was correlated with lower susceptibility to infection, but the effect of VPD was not tested in controlled experiments.

The present research was undertaken to identify environmental effects on host susceptibility. The specific objectives were to correlate changes in susceptibility of rose flowers to infection by B.cinerea with environmental conditions in a production greenhouse and to test the effects of specific environmental factors.

\section{Materials and Methods}

Greenhouse study. Greenhouse environmental conditions were monitored in a cut rose production greenhouse at Dillon Floral, Bloomsburg, Pa., using a data logger (Easylogger; Omnidata International, Logan, Utah). Temperature was measured with a thermistor (Omnidata model TP10) and relative humidity (RH) was measured with a capacitance-type solid state sensor (model HMP; Vaisala). These sensors were mounted in an aspirated duct that was maintained over the center of a flower bed at the height of the flower buds.

The presence of condensation was measured with an electrical impedance grid (model LWS10; Omnidata) mounted on the outside of the aspirated duct (Gillespie and Kidd, 1978). Raw voltage output from the sensor was converted to wetness values on a 0 (dry) to 1 (saturated) scale using the equation from Omnidata (1985):

$W=\left(V_{\text {out }}-V_{\text {dry }}\right) \times 1 /\left(V_{\text {wet }}-V_{\text {dry }}\right)$

where $\mathrm{W}=$ wetness value, $\mathrm{V}_{\text {out }}=$ output voltage from sensor, $\mathrm{V}_{\text {dry }}$ = output voltage at dryness and $\mathrm{V}_{\text {wet }}=$ output voltage at saturation. Sensor transition voltage was determined as described (Hammer, 1992). Wetness intervals were calculated by summing the number of minutes that the sensor was wet (i.e., output voltage > transition voltage) during each hour of data logging and dividing by 60 .

Air movement was measured with a constant temperature thermal anemometer (model 435 DC; Kurz Instruments, Monterey, Calif.) mounted over the center of a flower bed at the same height as the aspirated sensor duct. Photosynthetic photon flux (PPF) was measured with a quantum radiometer (model ES220; Omnidata ) mounted above the plant canopy about $1 \mathrm{~m}$ below the roof of the greenhouse. Canopy temperature was measured with an infrared 
thermometer (model 4000; Everest Interscience, Inc., Fullerton, Calif.). All sensors were read at 1 min intervals; the averages of these readings were recorded each hour. Vapor pressure deficits were estimated using the equation derived by Snyder and Shaw (1984):

$V P D=\left[6.108 \times e^{17.27 \times \mathrm{T} / \mathrm{T}+237.3}\right] \times[1-R H / 100] / 10$

where $\mathrm{VPD}=$ vapor pressure deficit in $\mathrm{kPa}, \mathrm{T}=$ air temperature in $\mathrm{C}$, and $\mathrm{RH}=$ percent relative humidity.

Fungicides were applied on only three occasions during the study. Benomyl and dodomorph acetate were applied to control powdery mildew on 14 Sept. 1989, and benomyl was applied to control powdery mildew on 1 Nov. 1989. Benomyl was applied on 22 Nov. 1989, to control Botrytis. Fungicide withdrawal period was calculated as the number of days between harvest and the most recent fungicide application.

Isolates of Botrytis cinerea were obtained from infected rose petals and grown on potato dextrose agar at 20C. Conidia were harvested from 13-day-old cultures and stored at-20C on silica gel as described previously (Smith and Onions, 1983). To produce inoculum the stored conidia were seeded onto media containing 1 $\mathrm{g} \mathrm{K}_{2} \mathrm{HPO}_{4}, 0.5 \mathrm{~g} \mathrm{MgSO}_{4} \cdot 7 \mathrm{H}_{2} \mathrm{O}, 0.5 \mathrm{~g} \mathrm{KCl}, 0.01 \mathrm{~g} \mathrm{FeSO}_{4} \cdot 7 \mathrm{H}_{2} \mathrm{O}, 2$ $\mathrm{g}$ L-asparagine monohydrate, $20 \mathrm{~g}$ glucose, and $20 \mathrm{~g}$ agar/liter (Phillips et al., 1987). Cultures were grown at $21 \pm 1 \mathrm{C}$ under a 12 $\mathrm{h}$ photoperiod from a cool white fluorescent lamp.

Conidia were washed from 14-day-old cultures with autoclaved deionized water, strained through cheesecloth, vortexed with 1 drop of Tween-20, and centrifuged for $10 \mathrm{~min}$ at $2000 \times \mathrm{g}$. Pelleted conidia were resuspended in autoclaved deionized water, counted with a hemacytometer, and diluted in autoclaved deionized water.

'Moonlight' rose flowers were harvested at commercial maturity (sepals partially reflexed and outer two petals unfolded) at monthly intervals from the production greenhouse and stored at 2 to $4 \mathrm{C}$ until inoculation. At each harvest date, inoculum concentration/disease severity (IC/DS) tests were used to quantify susceptibility to infection (Hammer and Evensen, 1994; Marois et al., 1988). Rose stems were recut $3 \mathrm{~cm}$ below the receptacle, and individual flowers were inoculated with $0,500,1000,2000$, or 4000 conidia/ml by spraying with a Preval spray unit (Precision Valve, Yonkers, N.Y.). The flowers were incubated for 2 days at $21 \mathrm{C}$ in clear plastic boxes with the stems submerged in deionized water and the flowers supported on wire racks above the water. The water in the bottoms of the containers maintained high humidity and water droplets were present on the flowers throughout incubation. Disease severity was determined by counting the number of lesions on each flower. For each test, there were five inoculum concentrations with 12 replicate flowers inoculated at each concentration. The number of lesions per flower (disease severity) was regressed on inoculum concentration. Relative susceptibility was defined as the slope of the IC/DS relationship $\times 100$ (Marois et al., 1988). (Multiplication by 100 is used to place relative susceptibility on a convenient scale.)

Overall mean values for each environmental factor measured were calculated by averaging hourly readings ( 0100 to $2400 \mathrm{HR})$ for the 5-week, 3-week, 2-week, 1-week, and 3-day periods preceding each harvest. Environmental factors with the greatest impact on susceptibility were selected by correlating these overall means with the relative susceptibility for each harvest. A multiple regression model was constructed using a stepwise regression procedure with disease severity as the dependent variable. The independent variables evaluated were inoculum concentration, the selected environmental factors, and the environmental factor $\times$ inoculum concentration interactions. All analyses were performed using SAS (SAS Inst., Cary, N.C.)

Growth chamber study. 'Moonlight' rose plants were potted in $15.5 \mathrm{~cm}$ standard pots using Metro Mix 500 medium (Grace Sierra, Fogelsville, $\mathrm{Pa}$.) and grown in the greenhouse. Plants were fertilized weekly with $180 \mathrm{mg} \cdot$ liter $^{-1} \mathrm{~N}$ from $15 \mathrm{~N}-7 \mathrm{P}-14 \mathrm{~K}$ (Peters 15 16-17 Peat-lite special, Grace Sierra, Fogelsville, Pa.) After 6 weeks uniform plants were selected, pruned to 5-leaflet leaves 30 to $40 \mathrm{~cm}$ above the pot rims, and randomly assigned to treatments in four growth chambers (model GC-15; Environmental Growth Chambers, Chagrin Falls, Ohio). There were 32 plants, spaced 23 $\times 20 \mathrm{~cm}$ on center, in each $185 \times 80$-cm chamber.

Plants were grown under an $18 \mathrm{~h}$ photoperiod from cool white fluorescent and incandescent lamps, which were maintained about $30 \mathrm{~cm}$ above the top of the canopy. The PPF at the tops of the canopies for the 4 crop cycles were $736 \pm 12,638 \pm 56,660 \pm 27$, and $600 \pm 26 \mu \mathrm{mol} \cdot \mathrm{m}^{-2} \cdot \mathrm{s}^{-1}$ (mean $\pm \mathrm{SD}$ among the four chambers). Temperature setpoints were $21 \mathrm{C}$ day and $17 \mathrm{C}$ night. RH setpoints were $85 \%$ day, $90 \%$ night for the high $\mathrm{RH}$ chambers, and $60 \%$ day, $90 \%$ night for the low RH chambers. Temperature and RH changes were ramped linearly over $30 \mathrm{~min}$ at the start of the light and dark periods. Temperature and RH were recorded hourly. For each crop cycle the overall mean day and night temperatures were within $0.2 \mathrm{C}$ of the setpoints, however, the RH setpoints were not maintained. The overall mean humidities achieved were $80 \%$ day, $91 \%$ night for the high RH treatments and $65 \%$ day, $90 \%$ night for the low RH treatments. This resulted in overall daytime VPDs of 0.49 and $0.86 \mathrm{kPa}$ for the high and low RH treatments, respectively.

Two fans (12-cm diameter, $0.54 \mathrm{~m}^{3} \cdot \mathrm{s}^{-1}$ capacity) were used to circulate air in each high wind chamber. The fans were suspended in diagonally opposite corners, $20 \mathrm{~cm}$ from the side walls, $30 \mathrm{~cm}$ from the end walls, and $15 \mathrm{~cm}$ below the fluorescent tubes. The airflow from each fan was directed away from the nearest end wall and parallel with the long dimension of the chamber. Wind velocities at the top of the mature canopy were measured with an omnidirectional constant temperature thermal anemometer (Model 1640; TSI, St. Paul). The overall mean wind speeds were $0.18 \mathrm{~m} \cdot \mathrm{s}^{-1}$ in the low wind treatments and $0.55 \mathrm{~m} \cdot \mathrm{s}^{-1}$ in the high wind treatments. The presence of condensation was measured only for the last crop using electrical impedance grids (Model 237; Campbell Scientific) mounted $30 \mathrm{~cm}$ below the fluorescent tubes in the center of each chamber. Mean wetness intervals ranged from $0.03 \%$ to $0.2 \%$.

Pots were irrigated once daily for the first 2 weeks of each cropping period, and twice daily thereafter with a nutrient solution containing $1 \mathrm{~g}$ Peters Hydro-Sol, $364 \mathrm{mg} \mathrm{Ca}\left(\mathrm{NO}_{3}\right)_{2} \bullet \mathrm{H}_{2} \mathrm{O}$ (Peters $15.5-0-0), 160 \mathrm{mg} \mathrm{NH} \mathrm{NO}_{3}, 44 \mathrm{mg} \mathrm{MgSO}_{4} \cdot 7 \mathrm{H}_{2} \mathrm{O}$, and $0.2 \mathrm{mg}$ $\mathrm{CuSO}_{4} \cdot 5 \mathrm{H}_{2} \mathrm{O} /$ liter of distilled water. Pots also were leached once weekly with distilled water. Abamectin $\left(310 \mu l \cdot\right.$ liter $^{-1}$ Avid 0.15 EC, Merck, Rahway, N.J.) and Bifenthrin (720 mg.liter ${ }^{-1}$ Talstar 10WP, FMC Corp., Philadelphia, Pa.) were applied once during each crop cycle to control spider mites and western flower thrips. No fungicides were applied during these experiments.

Flowers were harvested at commercial maturity and stored at 2 $\pm 1 \mathrm{C}$ in a hydrating solution (35.8 $\mathrm{mg}$ 8-hydroxy quinoline hemisulfate, $81.5 \mathrm{mg}$ citric acid monohydrate, $441 \mathrm{mg} \mathrm{CaCl}_{2}$ $2 \mathrm{H}_{2} \mathrm{O}, 1.47 \mathrm{~g} \mathrm{MgSO}_{4} \cdot 7 \mathrm{H}_{2} \mathrm{O}$, and $4 \mathrm{mg} \mathrm{NaOCl} /$ liter of deionized water). When sufficient flowers were accumulated (typically 5 to 7 days), they were inoculated with 0 or 4000 conidia $/ \mathrm{ml}$, incubated, and evaluated as described above for IC/DS experiments. The inoculum levels were chosen to maximize precision of the slope estimates using the limited number of flowers available (Neter et al., 1985).

At the end of each cropping cycle (about 40 days after pruning), 
plants were removed from the growth chambers and each shoot was pruned to a five-leaflet leaf. Plants were randomly reassigned to the chambers and the growing cycle repeated.

This experiment was a complete factorial with two wind levels, two RH levels, and two inoculum levels in a split plot design. Each crop constituted a block, and each growth chamber was a main plot

Table 1. Results of inoculum concentration/disease severity (IC/DS) tests on 'Moonlight' rose flowers harvested from a production greenhouse on 9 dates.

\begin{tabular}{lccc}
\hline \hline $\begin{array}{l}\text { Harvest } \\
\text { date }\end{array}$ & $\begin{array}{c}\text { Background } \\
\text { infection }^{\mathrm{z}}\end{array}$ & $\begin{array}{c}\text { Relative } \\
\text { susceptibility }\end{array}$ & $r^{2^{\mathrm{x}}}$ \\
\hline 31 Aug. 1989 & $0.5 \pm 0.9$ & 2.98 & 0.73 \\
12 Oct. 1989 & $2.3 \pm 2.3$ & 2.34 & 0.74 \\
9 Nov. 1989 & $5.8 \pm 4.1$ & 2.26 & 0.77 \\
17 Dec. 1989 & $4.7 \pm 3.1$ & 2.56 & 0.74 \\
25 Jan. 1990 & $37.0 \pm 13.4$ & 3.41 & 0.70 \\
22 Mar. 1990 & $18.2 \pm 5.8$ & 3.65 & 0.82 \\
24 Apr. 1990 & $11.0 \pm 7.1$ & 4.06 & 0.79 \\
29 May 1990 & $16.3 \pm 9.2$ & 3.60 & 0.80 \\
26 June 1990 & $7.6 \pm 4.6$ & 3.89 & 0.82 \\
\hline
\end{tabular}

${ }^{\mathrm{z}}$ Number of lesions that developed on flowers at the 0 conidia/ml inoculum level, i.e., flowers were sprayed with autoclaved deionized water before incubation. Values are means of 12 flowers \pm SD.

${ }^{\mathrm{y}}$ Slope of the IC/DS relationship $\times 100$.

${ }^{\mathrm{x}}$ Coefficient of simple determination for the IC/DS regression. within the blocks. Wind and RH were the main plot factors. Two of the growth chambers were not equipped for dehumidification. Thus, the low RH treatments were assigned to the same chambers for all four crops and RH was confounded with chamber. Each plastic incubation box constituted a subplot and inoculation was the subplot factor. There were eight subplots per crop, each containing one rose from each growth chamber at each inoculum concentration.

\section{Results}

Greenhouse study. Flowers were harvested on nine occasions. The relative susceptibilities ranged from 2.26 to 4.06 , and the coefficients of determination ranged from 0.70 to 0.82 (Table 1 ). The relative humidity sensor malfunctioned during the data logging periods before two of the harvests (24 Apr. and 26 June 1990). Thus, correlations involving RH or VPD were calculated using data from the remaining seven harvests. Susceptibility was not significantly correlated with relative humidity or VPD (Table 2), so further analyses were based on data from all nine harvest dates.

Relative susceptibility was not correlated with means of RH, VPD, air temperature or leaf temperature (Table 2). Mean VPD during the daytime hours of 0800 to $1900 \mathrm{HR}$ (as calculated by Marois et al., 1988) ranged from 0.42 to $1.10 \mathrm{kPa}$. Susceptibility was not correlated with mean daytime VPD or with daytime RH or air temperature $(P>0.44$, data not presented). Susceptibility was directly correlated with mean wind speeds and mean leaf to air temperature gradients, and inversely correlated with mean wetness

Table 2. Correlations among relative susceptibility of rose flowers to infection by Botrytis cinerea and mean environmental conditions in the production greenhouse for the 5-week periods before each harvest.

\begin{tabular}{|c|c|c|c|c|c|c|c|c|c|}
\hline & $\begin{array}{l}\text { Background } \\
\text { infections }\end{array}$ & RH & VPD & $\begin{array}{l}\text { Fungicide } \\
\text { application }\end{array}$ & $\begin{array}{l}\text { Fungicide } \\
\text { withdrawal }\end{array}$ & $\begin{array}{l}\text { Temperature } \\
\text { gradient }\end{array}$ & $\begin{array}{l}\text { Wetness } \\
\text { value }\end{array}$ & $\begin{array}{l}\text { Wetness } \\
\text { interval }\end{array}$ & $\begin{array}{l}\text { Wind } \\
\text { speed }\end{array}$ \\
\hline \multirow{2}{*}{ Susceptibility } & $0.44^{\mathrm{z}}$ & 0.47 & -0.19 & -0.89 & 0.89 & 0.83 & -0.94 & -0.92 & 0.97 \\
\hline & $0.23^{y}$ & 0.28 & 0.69 & 0.0013 & 0.0015 & 0.0055 & 0.0003 & 0.0005 & 0.0001 \\
\hline \multirow[t]{2}{*}{ Wind speed } & 0.60 & 0.61 & -0.33 & -0.90 & 0.84 & 0.88 & -0.97 & -0.97 & \\
\hline & 0.085 & 0.15 & 0.47 & 0.0009 & 0.0047 & 0.0019 & 0.0001 & 0.0001 & \\
\hline \multirow[t]{2}{*}{ Wetness interval } & -0.65 & -0.56 & 0.25 & 0.94 & -0.73 & -0.91 & 0.99 & & \\
\hline & 0.059 & 0.19 & 0.59 & 0.0002 & 0.024 & 0.0007 & 0.0001 & & \\
\hline \multirow[t]{2}{*}{ Wetness value } & -0.94 & -0.52 & 0.22 & 0.94 & -0.75 & -0.92 & & & \\
\hline & 0.0002 & 0.23 & 0.63 & 0.0002 & 0.021 & 0.0005 & & & \\
\hline \multirow{2}{*}{$\begin{array}{c}\text { Temperature } \\
\text { gradient }\end{array}$} & 0.77 & 0.33 & -0.36 & -0.80 & 0.56 & & & & \\
\hline & 0.016 & 0.46 & 0.43 & 0.0090 & 0.12 & & & & \\
\hline \multirow{2}{*}{$\begin{array}{l}\text { Fungicide } \\
\text { withdrawal }\end{array}$} & 0.16 & 0.55 & -0.32 & -0.77 & & & & & \\
\hline & 0.67 & 0.20 & 0.95 & 0.0157 & & & & & \\
\hline \multirow{2}{*}{$\begin{array}{l}\text { Fungicide } \\
\text { application }\end{array}$} & -0.19 & -0.43 & -0.030 & & & & & & \\
\hline & 0.63 & 0.33 & 0.95 & & & & & & \\
\hline \multirow[t]{2}{*}{ VPD } & -0.70 & -0.66 & & & & & & & \\
\hline & 0.078 & 0.11 & & & & & & & \\
\hline \multirow[t]{2}{*}{$\mathrm{RH}$} & -0.16 & & & & & & & & \\
\hline & 0.20 & & & & & & & & \\
\hline
\end{tabular}

${ }^{\mathrm{z}}$ Pearson product-moment correlation $(r)$.

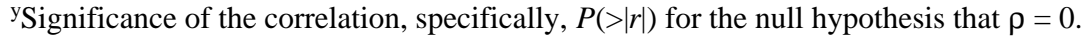


Table 3. Environmental and cultural conditions in the rose production greenhouse for the periods before each harvest. Values for environmental conditions are the overall means for the 5-week periods preceding each harvest.

\begin{tabular}{|c|c|c|c|c|c|c|c|c|}
\hline $\begin{array}{l}\text { Harvest } \\
\text { date }\end{array}$ & $\begin{array}{l}\mathrm{RH} \\
(\%)\end{array}$ & $\begin{array}{l}\text { VPD } \\
(\mathrm{kPa})\end{array}$ & $\begin{array}{c}\text { Fungicide } \\
\text { applications }{ }^{\mathrm{z}}\end{array}$ & $\begin{array}{c}\text { Fungicide } \\
\text { withdrawal }^{\mathrm{y}}\end{array}$ & $\begin{array}{l}\text { Temperature } \\
\text { gradient } \\
\text { (C) }\end{array}$ & $\begin{array}{l}\text { Wetness } \\
\text { value } \\
\left(0 \text { to } 1^{\mathrm{x}}\right)\end{array}$ & $\begin{array}{l}\text { Wetness } \\
\text { interval } \\
\left(\% \text { time }^{\mathrm{w}}\right)\end{array}$ & $\begin{array}{l}\text { Wind } \\
\text { speed } \\
\left(\mathrm{m} \cdot \mathrm{s}^{-1}\right)\end{array}$ \\
\hline 31 Aug. 1989 & 80.2 & 0.634 & 0 & 75 & 0.5 & 0.251 & 38.1 & 0.120 \\
\hline 12 Oct. 1989 & 80.5 & 0.503 & 1 & 27 & 0.3 & 0.494 & 72.7 & 0.079 \\
\hline 9 Nov. 1989 & 84.2 & 0.393 & 1 & 7 & 0.1 & 0.516 & 79.4 & 0.066 \\
\hline 17 Dec. 1989 & 77.9 & 0.506 & 1 & 24 & 0.5 & 0.510 & 85.9 & 0.070 \\
\hline 25 Jan. 1990 & 83.9 & 0.367 & 0 & 63 & 1.2 & 0.058 & 2.4 & 0.201 \\
\hline 22 Mar. 1990 & 82.5 & 0.444 & 0 & 119 & 1.3 & 0.006 & 0.3 & 0.201 \\
\hline 24 Apr. 1990 & $--^{v}$ & --- & 0 & 152 & 0.9 & 0.005 & 0.3 & 0.225 \\
\hline 29 May 1990 & 86.1 & 0.443 & 0 & 187 & 0.3 & 0.089 & 9.7 & 0.211 \\
\hline 26 June 1990 & --- & --- & 0 & 215 & 0.9 & 0.147 & 21.4 & 0.203 \\
\hline
\end{tabular}

${ }^{\mathrm{z}}$ Number of fungicide sprays applied in the 5-week period before harvest.

yDays between harvest and the most recent fungicide application (whether or not that application occurred within the 5-week period before harvest).

${ }^{x}$ The scale is 0 to 1 where $0=$ air dry sensor and $1=$ water-saturated sensor.

wercentage of time that the sensor was wet.

vData not recorded due to failure of the RH sensor.

intervals and mean wetness values for the 5 -week periods preceding harvest (Tables 2 and 3). When the environmental conditions were averaged over shorter periods (i.e., 21, 14, 7, or 3 days before harvest) similar correlations were observed (data not presented). For each period, wind speed was the variable most strongly correlated with susceptibility. For each of the four environmental variables means for the different periods were highly correlated with each other, but susceptibility was most strongly correlated with means for the 5-week periods before harvest (Table 4).

The 5-week means for wind speed, wetness value, wetness interval, and temperature gradient were highly correlated with each other $(r>0.85$, Table 3$)$. When the same correlations were calculated using the hourly data points from the periods preceding all nine harvests, wetness values and intervals were highly inversely correlated with wind speeds $(r>0.65)$, but the correlation between wind speed and temperature gradient was much weaker $(r=0.25)$.

When susceptibility was regressed against wind speed the resulting model was highly significant $(P<0.001)$ with $r^{2}=0.94$ (Table 5); however, the effect of wind speed was confounded with harvest date. That is, susceptibility increased over time from the beginning of the study (Fig. 1).

Susceptibility also was inversely correlated with the number of fungicide sprays, and directly correlated with fungicide withdrawal time (Tables 2 and 3 ). The correlation between susceptibility and number of fungicide applications was not significant for periods shorter than 35 days before harvest $(P>0.1$, data not presented).

The factors selected for further analysis were wind speed, wetness interval, wetness value, temperature gradient, number of fungicide applications, and fungicide withdrawal time. Mean values for each environmental factor for the 5-week periods before each harvest were used. The stepwise regression procecalculated. dure identified inoculum concentration, temperature gradient, and the wind speed $\times$ inoculum concentration interaction as important regressors for lesion count. A maximum $R^{2}$ selection procedure selected these same regressors for the best four-variable model to explain lesion count. The following multiple regression model was constructed:

Model I: $Y=4.0+0.017\left(X_{1}\right)+23.6\left(X_{2}\right)+0.1\left(X_{1}\right)\left(X_{3}\right)$

where $\mathrm{Y}=$ lesions per flower, $\mathrm{X}_{1}=$ inoculum concentration in conidia per $\mathrm{ml}_{1} \mathrm{X}_{2}=$ temperature gradient in $\mathrm{C}$, and $\mathrm{X}_{3}=$ wind speed in $\mathrm{m} \cdot \mathrm{s}^{-1}$. The model was highly significant $(P<0.001)$ with $R^{2}=$ 0.79 and each of the regressors had large partial $F$ values (Table 6). This model and alternative models, which included wetness and fungicide variables, were evaluated using partial $\mathrm{F}$ tests, correlation coefficients, examination of residuals, and Mallows' $\mathrm{C}_{\mathrm{p}}$ statis-

Table 4. Correlations among the susceptibility of rose flowers to infection by Botrytis cinerea and mean wind speed measured over various intervals before each harvest.

\begin{tabular}{llllll}
\hline \hline & \multicolumn{5}{c}{ Wind speed (mean) } \\
\cline { 2 - 6 } & 35 day $^{\mathrm{z}}$ & 21 day & 14 day & 7 day & 3 day \\
\hline Susceptibility & $0.97^{\mathrm{y}}$ & 0.93 & 0.91 & 0.89 & 0.86 \\
Wind speed & $0.0001^{\mathrm{x}}$ & 0.0003 & 0.0006 & 0.0014 & 0.0032 \\
3 day mean & & & & & \\
& 0.88 & 0.89 & 0.92 & 0.97 & \\
7 day mean & 0.0018 & 0.0013 & 0.0005 & 0.0001 & \\
& 0.90 & 0.96 & 0.98 & & \\
& 0.0009 & 0.0001 & 0.0001 & & \\
14 day mean & 0.93 & 0.99 & & & \\
& 0.0003 & 0.0001 & & & \\
21 day mean & 0.96 & & & & \\
& 0.0001 & & & & \\
& & & & & \\
\end{tabular}

$\overline{\mathrm{z}}$ Length of the time period immediately preceding each harvest for which the mean wind speed was

yPearson product-moment correlation $(r), \mathrm{n}=9$.

${ }^{x}$ Significance of the correlation, specifically, $P(>|r|)$ under the null hypothesis that $\rho=0$. 
Table 5. Analysis of variance for the effect of wind speed during production on relative susceptibility of rose flowers to infection to Botrytis cinerea.

\begin{tabular}{lcccc}
\hline \hline Source & df & Mean square & F ratio & $P(>\mathrm{F})$ \\
\hline Wind speed & 1 & 3.48 & 107 & $<0.001$ \\
Error & 7 & 0.032 & & \\
\hline
\end{tabular}

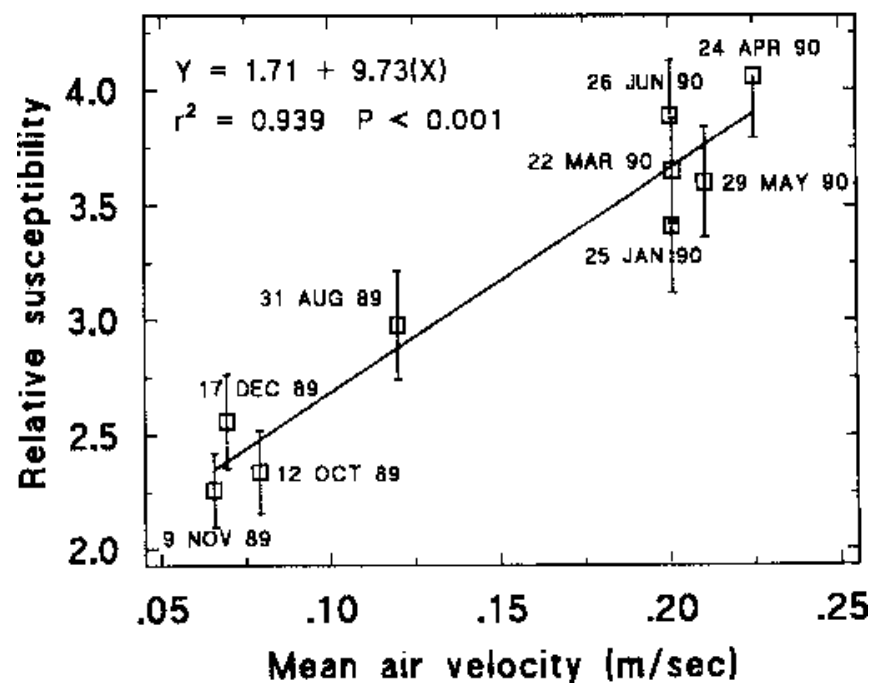

Fig. 1. Regression of relative susceptibility of rose flowers to postharvest infection by Botrytis cinerea on mean wind speed during production. Relative susceptibility is the estimated slope of the IC/DS relationship $\times 100$. Error bars represent SE of the transformed slope estimate. The date of harvest is shown beside each point.

tic (Neter et al., 1985). In all cases, the wind speed $\times$ inoculum concentration interaction was more highly significant than any other environmental factor $\times$ inoculum concentration interaction. When added to Model I, other variables contributed no new information as determined by partial F tests. Model I had the best combination of large $R^{2}$, large $\mathrm{F}$ ratio, and small bias (as determined by $\mathrm{C}_{\mathrm{p}}$ ) of all the models evaluated.

Growth chamber study. Susceptibility was higher for flowers grown under high wind (Fig. 2), as indicated by the significant wind $\times$ inoculation interaction (Table 7 ). High humidity increased disease severity at both inoculum levels, as indicated by the significant main effect, but the $\mathrm{RH} \times$ inoculation interaction was not significant (Fig. 2, Table 7). The short wetness intervals recorded in the chambers were not correlated with wind treatment (data not presented).

\section{Discussion}

IC/DS tests, as described by Marois et al. (1988) and Hammer and Evensen (1994) were used to measure susceptibility. Disease severity was regressed on inoculum concentration and the slope of the regression relationship was used as a quantitative measure of susceptibility. Uniform inoculum was applied and flowers were incubated under controlled conditions. While background infection levels (those infections not caused by laboratory inoculation) differed among sampling dates, such infections increased the disease severity at all inoculum levels. Higher background infection levels at some harvest dates shifted the IC/DS line up (higher disease severity at each inoculum concentration) and affected the intercepts of the regression relationships but not the slopes. Thus the slope of the relationship is a measure of susceptibility that is independent of direct effects of the production environment on the pathogen and is not biased by naturally occurring inoculum levels. On a given sampling date, however, background infections did contribute to the variability in disease severity observed at each inoculum concentration.

Analyses of the data collected in the greenhouse study indicated that wind speed was an important determinant of susceptibility. A simple linear regression model with wind speed as the independent variable accounted for $94 \%$ of the variability in susceptibility (Fig. 1). Marois et al. (1988) used a similar model to describe the relationship between susceptibility and VPD, however, such models treat each susceptibility value as a point observation of a dependent variable when it is actually an estimated slope with an associated variance. These simple regression models under-represent the variability in the data and have artificially large $r^{2}$ values. To address this problem, a multiple regression model was built by combining IC/DS data from the nine harvest dates (Table 1) with the mean environmental conditions for each date (Table 3). Disease severity, the dependent variable, was regressed on three independent variables (inoculum concentration, wind speed, temperature gradient) and their interactions. In this model, wind speed had a significant interactive effect with inoculum concentration, indicating that the wind speed during production changed the slope of the IC/DS relationship. That is, it significantly affected host susceptibility.

Susceptibility also was correlated with leaf to air temperature gradient, wetness value, and wetness interval. However, these variables were also highly correlated with wind speed. Increased wind speed hastens drying of condensation by breaking up boundary layers. Wind may also affect temperature gradients by increasing transpirational cooling and convective heat transfer between the leaves and air (Nobel, 1983). Physically, the larger temperature gradients and smaller wetness values might be secondary effects of increased air movement. When the larger data set of hourly means was analyzed, wetness conditions were again correlated with wind speeds. Thomas et al. (1988) reported that increasing wind speeds from 0 to $0.6 \mathrm{~m} \cdot \mathrm{s}^{-1}$ greatly increased evaporation. These facts strongly suggested a causal relationship between wind speed and wetness, in the greenhouse study.

In contrast, the hourly means of wind speed and temperature gradient were not strongly correlated. We believe that changes in wind speed were not the sole or primary determinants of the changes in temperature gradient and that the correlation between the 5-week means of wind and temperature gradient was coincidental.

Whether the relationships between wind, wetness and tempera-
Table 6. Analysis of variance for the multiple regression model of disease severity regressed on inoculum concentration and environmental conditions.

\begin{tabular}{lcccccc}
\hline Source & df & $\begin{array}{c}\text { Type II } \\
\text { mean square }\end{array}$ & F ratio & $\begin{array}{c}\text { Type II } \\
\text { partial } r^{2}\end{array}$ & $P(>\mathrm{F})$ & $\begin{array}{r}\text { Parameter } \\
\text { Estimate }\end{array}$ \\
\hline Intercept & 1 & 1072 & 1.6 & --- & 0.20 & 4.0 \\
Inoculum concentration & 1 & 53212 & 80.9 & 0.131 & $<0.001$ & 0.017 \\
Temperature gradient & 1 & 24860 & 37.8 & 0.067 & $<0.001$ & 23.6 \\
Inoculum $\times$ wind speed & 1 & 54512 & 82.9 & 0.134 & $<0.001$ & 0.10 \\
Error & 535 & 658 & & & & \\
\hline
\end{tabular}




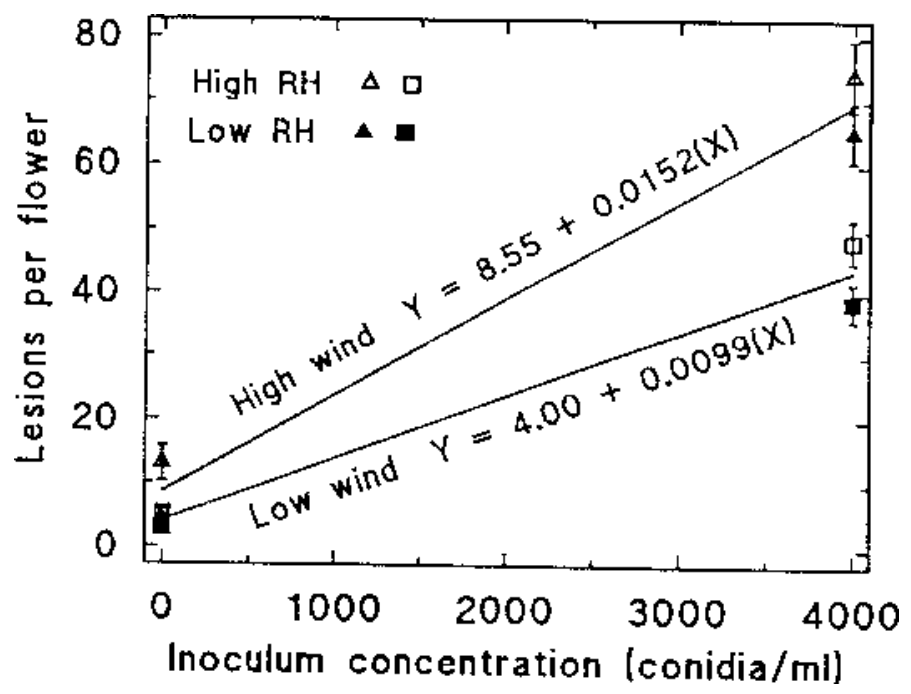

Fig. 2. IC/DS relationships for 'Moonlight' rose flowers grown under high (0.55 $\left.\mathrm{m} \cdot \mathrm{sec}^{-1}\right)$ or low $\left(0.18 \mathrm{~m} \cdot \mathrm{sec}^{-1}\right)$ wind speeds in growth chamber experiments. The difference in susceptibility between wind treatments (i.e., the treatment $\times$ inoculation interaction) was highly significant $(P=0.009)$ but the difference in susceptibility between RH treatments was not $(P=0.63)$.

ture gradient are causal or coincidental, correlation analyses cannot establish which factor is the most important physiologically in determining susceptibility. Of the four factors significantly correlated with susceptibility, wind speed was correlated most strongly and the wind speed $\times$ inoculum concentration interaction was selected first for the multiple regression model by the stepwise and maximum $\mathrm{R}^{2}$ procedures. When the wind $\times$ inoculum effect was included in the multiple regression model, interactions of the other factors with inoculum concentration did not contribute significant new information to the model. These results suggested that wind speed was indeed the primary or causative factor for the changes in susceptibility.

In contrast to the interactive effect of wind speed in the multiple regression model, the temperature gradient from leaves to air had a significant additive effect. Specifically, larger temperature gradients shifted the IC/DS line upward but did not affect its slope. We believe this was an effect on the spore load present at the time of harvest, rather than host susceptibility. The temperature gradient effect was highly significant and its inclusion removed considerable bias from the model. However, the contribution of temperature gradient to the model was smaller than the wind speed $\times$ inoculum concentration interaction, as indicated by $F$ ratios and coefficients of partial determination.

The confounding of wind speed with date of harvest can be explained by growth of the rose canopy. In commercial greenhouses, rose plants are pruned annually in summer and the canopy grows progressively taller through the production year. The production greenhouse at Dillon Floral was equipped with horizontal air flow fans suspended above the beds. Thus, the wind speed measured at the top of the rose canopy increased as the plants grew up into regions of faster airflow.

The significant correlation of susceptibility with fungicide application number and withdrawal may also be the result of multicollinearity in the data. These correlations with susceptibility were weaker than the other significant correlations and were not included as additive or interactive effects in the multiple regression model by stepwise or maximum $\mathrm{R}^{2}$ selection procedures. Fungicides were applied during only three of the crop cycles, all near the start of the study period (Fall 1989). When data from these three
Table 7. Analysis of variance for effects of wind speed and RH in growth chambers on susceptibility of rose flowers to postharvest infection by Botrytis cinerea.

\begin{tabular}{lccrr}
\hline \hline & df & Mean square & F ratio & $P(>\mathrm{F})$ \\
\hline Crop & 3 & 6756 & 5.9 & 0.017 \\
Wind & 1 & 14200 & 36.9 & $<0.001$ \\
RH & 1 & 3281 & 8.5 & 0.017 \\
Wind $\times$ RH & 1 & 156 & 0.4 & 0.540 \\
Error a & 9 & 385 & & \\
Inoculation & 1 & 155,589 & 212.0 & $<0.001$ \\
Wind $\times$ inoculation & 1 & 7,147 & 9.7 & 0.009 \\
RH $\times$ inoculation & 1 & 176 & 0.2 & 0.633 \\
Wind $\times$ RH & & & & \\
$\quad \times$ Inoculation & 1 & 207 & 0.3 & 0.606 \\
Error b & 12 & 734 & & \\
\hline
\end{tabular}

harvests were omitted from the analysis, the effect of wind on susceptibility remained highly significant (not presented). Additionally, the effect of wind was verified in growth chamber experiments where no fungicides were applied.

Our data suggest that wind speed during production affected the susceptibility of rose flowers to postharvest infection by B.cinerea. However, the evidence discussed above is correlative in nature and the effect of wind speed was confounded with both date of harvest and fungicide application. Therefore, controlled experiments were necessary to verify the wind effect. Since Marois et al. (1988) reported that VPD during production was correlated with susceptibility, a growth chamber experiment was designed to test the effects of wind speed and VPD while other environmental and cultural conditions were held constant.

In the growth chamber experiments, higher wind speed clearly increased susceptibility, substantiating the conclusions drawn from the commercial greenhouse data. In contrast to the greenhouse experiments, the effect of wind was not confounded with wetness interval in the growth chambers. Furthermore, the range of wetness intervals in the growth chambers $(0.03 \%$ to $0.2 \%)$ was a fraction of that observed in the production greenhouse $(0.3 \%$ to $86 \%)$. In fact, the differences in wetness data among growth chamber treatments were difficult to distinguish from calibration differences among sensors (Hammer, 1992).

The absence of a significant interaction between $\mathrm{RH}$ and inoculum concentration in the growth chamber experiment also corroborates the greenhouse study. We interpreted the small but significant main effect of humidity as a direct effect on the pathogen, not an effect on susceptibility. The high RH treatments resulted in higher spore loads on flowers at time of harvest and thereby increased disease severity at both inoculum levels.

We found no evidence for the effects of temperature, $\mathrm{RH}$, or VPD on susceptibility reported by Marois et al. (1988). Since Marois et al. (1988) recorded only temperature and RH and did not confirm the observed effect of VPD in controlled experiments, it is possible that VPD was collinear with wind speed or other factors in their data. However, the range of VPDs we observed were lower than those seen by Marois et al. (1988), they used a different cultivar ('Golden Wave'), and there were many other differences in climate, greenhouse structure, and cultural practices. While our results do not refute the effects of VPD reported by Marois et al. (1988), we have demonstrated that, in comparison to wind speed, RH and VPD have little or no effect on the susceptibility of 'Moonlight' roses under Pennsylvania growing conditions.

Under commercial conditions relative susceptibility varied from 2.26 to 4.06. If inoculum levels were constant, this would lead 
to a 1.7-fold difference in final disease outcome. However, this difference was small in comparison to the variability of naturally occurring infection levels (Table 1). In addition to affecting host susceptibility, environmental conditions exert important direct effects on pathogen growth and dispersal (Brown, 1942; Claflin et al., 1973; English et al., 1989; English et al., 1990; Sill et al., 1954; Thomas et al., 1988). For commercial purposes, manipulating the microclimate to inhibit infection, growth, and dispersal of the pathogen may be more effective than enhancing resistance.

Wind is more frequently associated with effects on pathogen growth and dispersal than with effects on susceptibility (Brown, 1942; Claflin et al., 1973; Sill et al., 1954; Thomas et al., 1988). Some increases in host plant susceptibility have been attributed to wind-induced damage to plant surfaces (Pitcairn and Grace, 1985; Sill et al., 1954; Wilson, 1984). Abrasion by windblown particles, rubbing together of plant parts, and leaf flexing can cause breaks in the cuticle and damage underlying cells (MacKerron, 1976; Michailides and Morgan, 1993; Wilson, 1984). Lower wind velocities, while not causing macroscopically visible damage, can alter epicuticular and cuticular waxes, and increase cuticular conductance (Pitcairn and Grace, 1985; Pitcairn et al., 1986). The wind speeds used in the studies cited (Brown, 1942; Claflin et al., 1973; MacKerron, 1976; Michailides and Morgan, 1993; Pitcairn and Grace, 1985; Pitcairn et al., 1986; Sill et al., 1954; Thomas et al., 1988; Wilson, 1984) were greater than $3 \mathrm{~m} \cdot \mathrm{s}^{-1}$ and caused surface alterations that were evident under SEM examination. Such wind speeds were much larger than those in the present research. It is possible that the low wind velocities in the present studies subtly altered cuticular deposition or structure. More mechanistic studies are needed to form sound hypotheses about the physiological basis for the effect of wind on susceptibility.

\section{Literature Cited}

Brown, J.G. 1942. Wind dissemination of angular leaf spot of cotton. Phytopathology 32:81-90.

Carre, D.D. 1984. The influence of atmospheric humidity and free water on germination and germ tube growth of Botrytis cinerea Pers. MS thesis. Oregon State Univ., Corvalis.

Claflin, L.E., D.L. Stuteville, and D.V. Armbrust. 1973. Wind-blown soil in the epidemiology of bacterial leaf spot of alfalfa and common blight of bean. Phytopathology 63:1417-1419.

English, J.T., A.M. Bledsoe, J.J. Marois, and W.M. Kliewer. 1990. Influence of grapevine canopy management on evaporative potential in the fruit zone. Amer. J. Enol. Viticult. 41:137-141.

English, J.T., C.S. Thomas, J.J. Marois, and W.D. Gubler. 1989. Microclimates of grapevine canopies associated with leaf removal and control of Botrytis bunch rot. Phytopathology 79:395-401.

Fletcher, J.T. 1985. The better ways of beating Botrytis. The Grower 103(16):19-21.

Gillespie, T.J. and G.E. Kidd. 1978. Sensing duration of leaf moisture retention using electrical impedance grids. Can. J. Plant Sci. 58:179187.

Gubler, W.D., J.J. Marois, A.M. Bledsoe, and L.J. Bettiga. 1987. Control of Botrytis bunch rot of grape with canopy management. Plant Dis. 71:599-601.

Hammer, P.E. 1992. Mechanisms of resistance to infection by Botrytis cinerea in rose flowers. PhD diss. The Pennsylvania State Univ., University Park.

Hammer, P.E. and K.B. Evensen. 1994. Differences between rose cultivars in susceptibility to infection by Botrytis cinerea. Phytopathology 84:1305-1312.

Hammer, P.E. and J.J. Marois. 1989. Nonchemical methods for postharvest control of Botrytis cinerea on cut roses. J. Amer. Soc. Hort. Sci. 114:100-106.

Hausbeck, M.K. and S.P. Pennypacker. 1991. Influence of grower activity and disease incidence on concentrations of airborne conidia of Botrytis cinerea among geranium stock plants. Plant Dis. 75:798-803.

Jarvis, W.R. 1977. Botryotinia and Botrytis Species: Taxonomy, Physiology, and Pathogenicity. Monograph no. 15. Can. Dept. of Agr., Ottawa.

MacKerron, D.K.L. 1976. Wind damage to the surface of strawberry leaves. Annals of Bot. 40:351-354.

Marois, J.J., J.C. Redmond, and J.D. MacDonald. 1988. Quantification of the impact of environment on the susceptibility of Rosa hybrida flowers to Botrytis cinerea. J. Amer. Soc. Hort. Sci. 113:842-845.

Michailides, T.J. and D.P. Morgan. 1993. Wind scab of French prune: Symptomatology and predisposition to preharvest and postharvest fungal decay. Plant Dis. 77:90-95.

Neter, J., W. Wasserman, and M.H. Kunter. 1985. Applied linear statistical models. 2nd ed. Irwin, Homewood, Ill.

Nobel, P.S. 1983. Biophysical plant physiology and ecology. Freeman, N.Y.

Phillips, D.J., D.A. Margosan, and B.E. Mackey. 1987. Size nuclear number and aggressiveness of Botrytis cinerea spores produced on media of varied glucose concentrations. Phytopathology 77:1606-1608.

Pitcairn, C.E.R. and J. Grace. 1985. Wind and surface damage, p. 115126. In: J. Grace (ed.). Effects of shelter on the physiology of plants and animals. Swets and Zeitlinger, Lisse, Netherlands.

Pitcairn, C.E.R., C.E. Jeffree, and J. Grace. 1986. Influence of polishing and abrasion on the diffusive conductance of leaf surface of Festuca arundinaceae Shreb. Plant Cell Environ. 9:191-196.

Sill, W.H., Jr., A.E. Lowe, R.C. Bellingham, and H. Fellows. 1954. Transmission of wheat streak-mosaic virus by abrasive leaf contacts during strong winds. Plant Dis. Rpt. 38:445-447.

Smith, D. and H.S. Onions. 1983. The preservation and maintenance of living fungi. Commonwealth Mycological Inst., Surrey, U.K.

Snyder, R.S. and R.H. Shaw. 1984. Converting humidity expressions with computers and calculators. Univ. of Calif. Coop. Ext. Lflt. 21372. Univ. of Calif., Berkeley.

Thomas, C.J., J.J. Marois, and J.T. English. 1988. The effects of wind speed, temperature, and relative humidity on development of aerial mycelium and conidia of B.cinerea on grape. Phytopathology 78:260 265.

Verhoeff, K. 1980. Infection and host-pathogen interactions, p. 158-180. In: J.R. Coley-Smith, K. Verhoeff and W.R. Jarvis (eds.). The biology of Botrytis. Academic Press, London.

Wilson, J. 1984. Microscopic features of wind damage to leaves of Acer pseudoplantanus L. Annu. Bot. 53:73-82.

Yunis, H., D. Shtienberg, Y. Elad, and Y. Mahrer, 1994. Qualitative approach for modelling outbreaks of grey mould epidemics in nonheated cucumber greenhouses. Crop Prot. 13:99-104. 